\title{
QUERER-SE LIVRE E QUERER-SE MORAL É UMA SÓ E MESMA DECISÃ 0: SIMONE DE BEAUVOIR E A ÉTICA DA AMBIGÜIDADE
}

\author{
Nathan Menezes Amarante Teixeira ${ }^{1}$ \\ Universidade Federal do Rio de Janeiro (UFRJ)
}

\begin{abstract}
RESUMO:
Este trabalho visa apresentar o pensamento ético de Simone de Beauvoir tal como é exposto em seu livro Por une morale de l'ambiguité. Neste livro, a autora retoma sua compreensão da existência humana dada em seu texto anterior, Pyrrhus et Cinéas, porém, desdobrando melhor sua análise e apresentando um princípio ético ambíguo posto que universal e singular simultaneamente, a partir do qual uma ética condizente ao existir humano seria esboçada. Assim, buscaremos aqui caracterizar propriamente como Simone de Beauvoir entende essa ética da ambigüidade, fundamentalmente a partir da compreensão da afirmação de que "querer-se livre e querer-se moral é uma só e mesma decisão".
\end{abstract}

PALAVRAS - CHAVE: Simone de Beauvoir; Ética; Ambiguidade; Situação; Liberação.

\section{TO WILL ONESELF MORAL AND TO WILL ONESELF FREE ARE ONE AND THE SAME DECISION: SIMONE DE BEAUVOIR AND THE ETHICS OF AMBIGUITY}

\begin{abstract}
:
This paper aims to present the ethical thinking of Simone de Beauvoir as it is exposed in her book Pour une morale de l'ambiguité. In this book, the author retakes her understanding of the human existence given in her previous text, Pyrrhus et Cinéas, unfolding better her analysis and presenting an ambiguous ethical principle as universal and singular at the same time from which an ethics consistent with human existence would be outlined. Thus, we will seek to characterize properly how Simone de Beauvoir understands this ethics of ambiguity, fundamentally from the comprehension of the affirmation that "to will oneself moral and to will oneself free are one and the same decision".
\end{abstract}

KEYWORDS: Simone de Beauvoir; Ethics; Ambiguity; Situation; Liberation.

\footnotetext{
${ }^{1}$ Doutorando em Filosofia na Universidade Federal do Rio de Janeiro (UFRJ), Rio de Janeiro Brasil. Bolsista CNPq. Email: nathanmateixeira@gmail.com 
Uma das colocações centrais de Pour une morale de l'ambiguite, através da qual Simone de Beauvoir explicita aquilo que seria a questão a ser trabalhada no texto, é dada logo na primeira parte, onde a autora diz: "uma moral da ambigüidade será uma moral que se recusará a negar a priori que os existentes separados possam ao mesmo tempo serem ligados entre si, que suas liberdades singulares possam forjar leis válidas para todos" (BEAUVOIR, 2013, p. 24). A apresentação de tal questão, como veremos, condiciona toda a argumentação da autora na sua busca de marcar que há a possibilidade de criação de um discurso ético a partir da própria estrutura da existência humana, fundamentalmente, que é "no conhecimento das condições autênticas [conditions authentiques] de nossa vida que devemos extrair a força para viver e as razões para agir (Ibidem, p. 14, grifo nosso). Dessa forma, é a partir deste pano de fundo que Simone de Beauvoir irá apresentar o que seria propriamente essa estrutura existencial visada como abertura ética e, portanto, como lugar no qual um conteúdo positivo ao agir é apresentado.

Antes, porem, da análise direta do texto em questão, é preciso marcar as colocações que a autora já havia feito em seu texto anterior de 1944, Pyrrhus et Cinéas, uma vez que estas são a base a ser retrabalhada em Pour une morale de l'ambiguité. Sem realizarmos uma explicação mais exaustiva, temos que nesse primeiro texto, Simone de Beauvoir apresenta a relação ambígua entre a experiência individual e a situação universal na qual esta se dá, a partir da consideração da ambigüidade presente na liberdade ontológica humana. Ou seja, para a autora, o estar lançado gratuitamente no mundo que marca o enraizamento da liberdade em uma situação e a configura como existência humana singular, é um movimento ambíguo de retomada e recriação das significações objetivadas na minha situação pela transcendência corporal. Assim que temos um primeiro "solo" como constituição subjetiva primeira pré-pessoal - uma intersubjetividade -, que por sua vez, é retomado e recriado pela transcendência posterior da consciência, cujo Nada que trás em si é ambíguo, uma vez que mantém a ambigüidade na sua relação com o corpo como mediação com sua situação.

Em suma, Pyrrhus et Cinéas nos apresenta que a liberdade humana está enraizada na sua situação, esta última é transcendida e levada mais além pela primeira sem ser negada, posto que nela "está engajada sua própria carne [chair]"2 (Ibidem, p. 305, grifo nosso). Como conseqüência, nosso ser no mundo com os outros mostra-se naquilo que Beauvoir coloca como uma estrutura de apelo, a partir da ideia de que minha situação apela a ser transcendida pela minha liberdade. Assim, cada agir meu é um retomar e recriar daquilo que minha situação me entrega enquanto trabalhada pelos outros, e meu agir é já alteração dessa situação configurando-se como "solo" a ser retomado e recriado pelos outros; em suma, agir é atender ao apelo dos outros sendo já apelo a estes, abertura recíproca enquanto um chamar a "fazer algo a partir de".

Assim, é sobre esta base que se dão as colocações do texto de 1947, especificamente, é tal ambigüidade que a autora retoma quando abre Pour une

\footnotetext{
2 É importante marcar apenas que esta colocação é do texto Pyrrhus et Cinéas, porém, aparece na citação como sequiência do mesmo texto da citação anterior, que é de Pour une morale de l'ambiguité, uma vez que ambos são publicados em conjunto pela Gallimard, conforme consta nas referencias bibliográficas.
}

TEIXEIRA, Nathan Menezes Amarante. Querer-se livre e querer-se moral é uma só e mesma decisão: Simone de Beauvoir e a 
morale de l'ambiguité escrevendo que "esta trágica ambivalência [tragique ambivalence] que o animal e a planta apenas sofrem, o homem a conhece, a pensa" (Ibidem, p. 11). Diz-se trágica tal condição ambígua, justamente porque ela nos coloca simultaneamente como transcendência subjetiva para além do dado, fim último da ação, e como "coisa esmagada pelos pés obscuros das outras coisas" (Ibidem, p. 11), objeto enraizado na situação a ser transcendido pelos demais. $O$ problema surge justamente pelo fato de que, sendo ser dotado da negatividade ambígua da consciência, o ser humano pensa sobre e a partir desta condição, e toda a construção filosófica posterior pode vir a ser - e segundo Beauvoir de fato o foi ${ }^{3}$ encobrimento ou negação desta ambigüidade. Porém, tal mascaramento, mais do que impedir o conhecimento desta estrutura existencial fundamental, gera um problema ético, na medida em que qualquer moral a ser apresentada será uma que comportará a mesma negligencia em lidar seriamente com a ambigüidade, sendo então uma moral afastada do próprio existir humano sobre o qual ela tem a pretensão de dizer algo.

Por isso, segundo Beauvoir, o existencialismo estaria em melhor posição de dar conta de uma moral condizente com o existir humano ambíguo, pois este "se define de início como uma filosofia da ambigüidade" (Ibidem, p. 14). O que está sendo pensado aqui como existencialismo é precisamente a análise existencial que a autora fez em seu texto anterior ${ }^{4}$, cujas principais conseqüências já mostramos, porém, é acrescentada uma definição importante, segundo a qual "Há um tipo original de vinculação [attachement] ao ser que não é a relação querer o ser, mas antes querer desvelar o ser [voiloir dévoiler l'être] (Ibidem, p. 19). Trata-se de uma qualificação que Simone de Beauvoir faz do movimento ambíguo do existir que incorporamos quando viemos à existência, identificado precisamente por Eva Gothlin como influencia da fenomenologia existencial de Heidegger ${ }^{5}$. Como aponta a

\footnotetext{
3 "Uma vez que existem homens e que eles vivem, todos eles sentem esta trágica ambigüidade da sua condição; mas uma vez que existem filósofos e que eles pensam, a maioria tentou encobri-la. Eles se esforçaram por reduzir o espírito à matéria, ou por reabsorver a matéria no espírito, ou por confundilos no seio de uma substância única. [...] E a moral que eles propuseram a seus discípulos possuía sempre o mesmo propósito: tratava-se de suprimir a ambigüidade ao se fazer pura interioridade ou pura exterioridade, ao se evadir do mundo sensível ou por ele ser engolido, ao ascender à eternidade ou se fechar no instante puro" (Ibidem, p. 12).

4 Não trabalharemos aqui as diferenciações entre Sartre e Simone de Beauvoir, posto não ser nosso propósito. Apenas marcamos que Simone de Beauvoir tem sua própria compreensão do existencialismo, na medida em que as suas considerações de Pyrrhus et Cinéas, que mostramos brevemente, são a sua própria análise existencial construída sobre inspiração da ontologia sartreana, mas ao mesmo tempo sobre modificação de algumas colocações desta. Portanto, quando Beauvoir busca explicar o que seria o existencialismo, trata-se da sua reflexão própria sobre este, e não uma repetição de uma explicação que já estaria presente em Sartre.

5 Segundo a comentadora, o pensamento de Simone de Beauvoir é melhor caracterizado quando se leva em consideração sua dimensão fenomenológica, além da dimensão existencial. Neste contexto apareceria a influencia de Heidegger, que para Eva Gothlin seria mais marcante do que em Sartre. Ela marca dois pontos fundamentais para isso; primeiro, tem-se que "Sartre rejeita o conceito heideggeriano de Mitsein em L'être et le néant", enquanto Beauvoir trabalha com ele desde o início pois, "apesar de o conceito de Mitsein não aparecer até Le deuxieme sexe, seu conteúdo é transmitido desde o inicio de Pour une morale de l'ambiguité através do conceito de interdependência" (GOTHLIN, 2001 , p. 46). O outro ponto seria justamente o uso da ideia de "desvelamento do ser", que explicaremos na seqüência do texto, em oposição direta a Sartre que trabalha com um "querer o ser".
}

TEIXEIRA, Nathan Menezes Amarante. Querer-se livre e querer-se moral é uma só e mesma decisão: Simone de Beauvoir e a 
comentadora, Beauvoir faria uso do conceito heideggeriano de Erschlossenheit, traduzido no francês por "dévoilement", dado por Heidegger na sua definição do ente humano como Dasein, onde se diz que "O Dasein é seu desvelamento [Das Dasein ist seine Erschlossenheit]" (HEIDEGGER, 1967, p. 133). Haveria então uma compreensão fundamental extraída por Simone de Beauvoir de tal termo, à luz de suas próprias análises existenciais, no qual o desvelar marcaria "que o mundo é investido de significações humanas" (GOTHLIN, 2001, p. 46), que o indivíduo interioriza e desvela em situação, que a existência humana é fundamentalmente uma abertura à criação significativa de sua situação, de modo que esta última apela sempre ao desvelar de algo já dado; principalmente, que esse desvelar é a própria existência em seu movimento livre de abertura a seu prolongamento no porvir. ${ }^{6}$.

A partir desta colocação, temos que a transcendência corporal que nos enraíza em um solo primeiro é a singularização carnal deste movimento livre da existência de querer desvelar o ser, é aí que temos nossa relação primeira com o ser enquanto apelo a ser desvelado. Esta qualificação marca mais a ambigüidade da relação entre liberdade e situação, ou seja, a preocupação recorrente de Beauvoir de mostrar que a situação não é mera passividade sobre a qual se exerce plenamente a liberdade, pois se tem antes uma relação ambígua de passividade e atividade de ambos os lados, pois a situação entrega já um ser, uma significação objetivada que pede a ser desvelada pela retomada e recriação da liberdade, de modo que aquilo que se desvela aparece como já estando encarnado pela liberdade que o faz aparecer já sendo outro, algo mais além ${ }^{7}$.

Entretanto, outro elemento oferecido pela autora para melhor caracterização da situação é dado quando esta aponta que se encontra tal noção de modo significativo a partir do pensamento marxista. Simone de Beauvoir diz:

\begin{abstract}
É interessante marcar que a noção de situação e o reconhecimento das separações que ela implica não é própria somente do existencialismo. Nos a encontramos também no marxismo [...] Marx não considera que certas situações humanas sejam em si e absolutamente preferíveis a outras: são as necessidades de um povo, as revoltas de uma classe que definem os propósitos e os fins. [...] e é a partir de um certo enraizamento [enracinement] singular no mundo histórico e econômico que esta vontade se lança em direção ao porvir [...] (BEAUVOIR, 2013, p. 25, grifo nosso).
\end{abstract}

Assim, segundo a autora, Marx também trabalharia com a noção de situação ao frisar em seu pensamento que "o homem não é um ser abstrato, ancorado fora do mundo", ou seja, "o homem é o mundo do homem" (MARX, 2010, p. 145). Neste

\footnotetext{
${ }^{6}$ Ainda de acordo com Eva Gothlin, porém em outro texto, Heidegger estaria preocupado com o fato de que o desvelamento [Erschlossenheit] seria a condição dada pelo ente humano para que qualquer coisa significativa apareça no mundo, seu modo de desvelamento sendo a compreensão. Já Beauvoir, "enfatizaria o aspecto 'desvelando', 'revelando"' (GOTHLIN, p. 48), na medida em que ela buscaria marcar que é um movimento contínuo e ambíguo da própria existência, que é mantido na incorporação subjetiva que cada ser humano faz ao vir a existir. Ainda, é também por tal foco no elemento de continuidade e ambigüidade que este teria importância ética.

7 Destacamos a importante colocação de Kristiana Arp, segundo a qual toda a estrutura ética fundamental do pensamento de Beauvoir estaria fundada "no conceito de sujeito situado" (ARP, 2001, p. 179), portanto, a partir da ambigüidade marcada em tal relação.
} 
sentido, é ancorada em uma situação que modifica e pela qual é modificada simultaneamente, que a transcendência humana se materializaria na construção desta situação já abrindo-a ao porvir. Como já visto antes, Simone de Beauvoir trabalha com uma noção de liberdade enraizada na situação deste seu texto de $1944^{8}$, marcando que os projetos humanos estão sempre enredados entre si a partir do "solo objetivo" comum da situação, estabelecendo-se que o cultivo coletivo da situação pela transcendência é a causa da estruturação do social e ao mesmo tempo meio da afirmação livre e subjetiva de cada indivíduo. Porém, com a indicação direta da influência marxista para compreensão da situação no texto posterior, temos a especificação de que o desvelamento do ser que a liberdade opera no movimento ambíguo é a objetivação em situação de uma reciprocidade dialética ontológica, que cria significações como estruturas sociais históricas as quais serão internalizadas como solo mediador a partir do qual os indivíduos exteriorizarão as relações entre si e suas respectivas constituições subjetivas.

Torna-se mais clara esta influência marxista quando nos atentamos para a questão do trabalho, tal como é apresentada nos Manuscritos de 1844. O ponto de partida de Marx ao lidar com a noção de trabalho é dado a partir da ideia de que os seres humanos são animais naturais na medida em que estão sujeitos às necessidades físicas e que, no atendimento destas necessidades a partir da produção coletiva do trabalho, acabam transformando esse ambiente em algo social. Portanto, "o ser humano é um animal trabalhador, cuja espécie consiste na transformação social do mundo natural" (BOUCHER, 2012, p. 38), de modo que o trabalho mostra-se como atividade essencial humana de uma simultânea transformação coletiva da sociedade e da existência de cada individuo, que trabalha a partir da objetivação social de seu trabalho e dos outros. Neste sentido, Marx afirma:

Na elaboração do mundo objetivo [é que] o homem se confirma, em
primeiro lugar e efetivamente como ser genérico. Esta produção é a sua
vida genérica operativa. Através dela a natureza aparece como a sua obra
e a sua efetividade (Wirklicheit). O objeto do trabalho é portanto a
objetivação da vida genérica do homem: quando o homem se duplica não
apenas na consciência, intelectualmente, mas operativa, efetivamente,
contemplando-se, por isso, a si mesmo num mundo criado por ele (MARX,
2004, p. 85).

A partir desta citação observamos que a estrutura de relação entre situação e liberdade e a consequente descrição da operação deste movimento livre que Simone de Beauvoir faz pode ser lida como uma espécie de tradução, para os termos existencialistas, da estrutura marxista de relação entre indivíduo e sociedade mediada pelo trabalho. Entendendo-se que o fundamental nessa postulação marxista é que "a atividade produtiva é, por conseguinte, mediadora na relação 'sujeito-objeto'

\footnotetext{
${ }^{8}$ É interessante que Beauvoir já em Pyrrhus et Cinéas defina a liberdade como enraizada na situação que é seu solo, como aparece quando a autora usa a imagem de jardim para definir tal relação. Assim, a indicação aqui de que Marx também trabalharia com a ideia de um ancoramento da atividade humana no social mostra-nos que a influência marxista em Beauvoir é já anterior à Por une morale de l'ambiguité, ainda, que tal influência é importante para as modificações que ela faz na ontologia sartreana apresentadas pela primeira vez neste seu texto inicial e sustentada e retrabalhada ao longo dos textos seguintes.
}

TEIXEIRA, Nathan Menezes Amarante. Querer-se livre e querer-se moral é uma só e mesma decisão: Simone de Beauvoir e a 
entre o ser humano e a natureza [...] que capacita o ser humano para levar um modo de existência humano" (MÉZÁROS, 2016, p. 80), vemos que a liberdade ontológica da pensadora francesa é colocada como trabalho constante na sua situação, ou seja, como cultivo de um retomar e recriar deste estar enraizado em um movimento que constitui o indivíduo subjetivamente e simultaneamente constitui os pontos de partida a serem retomados pelos outros.

Em suma, Beauvoir retoma de Marx a compreensão que este coloca no trabalho de que o essencial do ser humano é a atividade transcendente e livre de construção coletiva do seu meio e de si ao mesmo tempo, e ainda, que é pelo modo como esta atividade é estruturada objetivamente em situação coletiva que cada indivíduo a vive e a significa para si e para os demais. Portanto, é em termos de reciprocidade dialética (ambígua, em Beauvoir) que se deve compreender a relação da liberdade e situação mediada pelas possibilidades concretas abertas e estruturadas coletivamente. Assim, é neste movimento livre de desvelamento do ser que se elabora o mundo objetivo e que o ser humano se constitui subjetivamente ao se engajar nos seus projetos e se confirma como ser humano "genérico", como ser situado no meio dos outros diante da mesma necessidade ontológica e ambígua de trabalhar transcender coletivamente sua situação.

Deste modo, a estrutura ético-existencial de Simone de Beauvoir seria melhor caracterizada por aquilo que Mark Poster chama de um Marxismo existencial ${ }^{9}$, na medida em que esta coloca como ambígua a liberdade humana que transcende sua situação, já marcada por ela e nunca se desenraizando desta, coloca uma estrutura ontológica em relação direta com o social ao marcar que o existir humano é expressão e construção constante desta relação entre liberdade e situação. Assim, ao lidar diretamente com a ambigüidade desse movimento livre que nos ancora na existência e nela nos sustenta, a análise existencial de Simone de Beauvoir pode dar conta de uma ética condizente com o existir, pois é "retornando para esta liberdade que nós iremos descobrir um princípio de ação cujo alcance será universal" (Ibidem, p. 31). O que se obtém então, por tal retorno, é a percepção de que ao vir espontaneamente a existir, o ser humano sustenta em si tal movimento ambíguo de

\footnotetext{
${ }^{9}$ Segundo o comentador, marxismo existencialista seria entendido como "um Marxismo não leninista que conceitualiza a sociedade industrial avançada visando a possível eliminação das suas estruturas alienantes; que observa todas as relações cotidianas, não simplesmente as relações de produção, para fazer a sociedade inteligível; que toma do existencialismo o esforço de capturar os seres humanos no momento de sua criação ativa do mundo, na sua subjetividade" (POSTER, 1975, p. ix). Entretanto, o comentador atribui tal característica ao pensamento de Sartre tal como expresso em Critique de la raison dialeticque, mostrando que isso foi um esforço de Sartre de se aproximar mais do marxismo fundamentalmente a partir das criticas que recebeu ao L'être et le Néant. Porém, como vimos, o pensamento de Beauvoir é desde o início uma relação entre ambas as correntes de pensamento, ao tentar tornar mais "material" a liberdade ontológica sartreana na perspectiva de um ancoramento marxista desta no campo social; logo, a caracterização de Mark Poster é válida antes para Beauvoir do que para Sartre, que modifica suas estruturas ontológicas iniciais no texto de 1960 justamente a partir de uma influência do textos anteriores de Beauvoir. Jack Reynolds é preciso ao fazer tal apontamento na sua introdução ao pensamento de Simone de Beauvoir; falando da diferença desta em relação à Sartre o comentador diz: "ela [Beauvoir] de fato coloca muitos questionamentos ao existencialismo de Sartre. [...] seu interesse inicial pelo marxismo antecipou as modificações subseqüentes de Sartre em sua filosofia da liberdade, apresentada em seu último trabalho Crítica da razão dialética" (REYNOLDS, 2013, p. 200).
} 
fixar o ser e desenvolvê-lo. Sua transcendência lança-se ao mundo como fixação e abertura, cuja totalidade é um só "querer desvelar". É esse contínuo sustentar de tal movimento que faz com que hajam existências humanas situadas em um mundo significativo, de modo que coincidir com esta liberdade, afirmá-la positivamente nas minhas ações, é um querer-se livre e querer a criação contínua do mundo como cenário total das nossas situações. Como diz Beauvoir:

\begin{abstract}
Nós vimos que o desenho original [dessein originel] do homem é ambíguo: ele quer ser, e na medida em que ele coincide com esta vontade, ele falha; todos os projetos nos quais se atualiza seu querer-ser estão condenados, e os fins circunscritos por seus projetos permanecem miragens. Nestas tentativas abortadas, a transcendência humana é tragada em vão. Mas o homem quer a si também o desvelamento do ser, e se ele coincide com essa vontade ele ganha, pois o fato é que, por sua presença ao mundo o mundo torna-se presente. Mas o desvelamento do ser implica uma tensão perpétua para manter o ser a distância, para se arrancar ao mundo e se afirmar como liberdade: querer o desvelamento do mundo, querer-se livre, é um só e mesmo movimento [ vouloir le dévoilement du monde, se vouloir libre, c'est um seul et même mouvement] (Ibidem, p. 31, grifo nosso).
\end{abstract}

A liberdade ontológica que me lança ao mundo precisa dar-se materialmente como liberdade autêntica, esta sendo a decisão de coincidir com essa vontade de desvelar o ser, de me engajar em manter esse retomar e recriar no meu próprio agir que visa, através do seu conteúdo, "um fim que não é alguma coisa, mas precisamente o livre movimento da existência" (Ibidem, p. 38). Trata-se aqui da afirmação do "querer-se livre" passível de um alcance universal.

Entretanto, antes de detalhar melhor tal princípio, é preciso que nos ocupemos do fato de que Simone de Beauvoir vai mais além na sua busca de caracterizar essa relação original com o movimento do existir, ao colocá-la como a "paixão" humana, ou seja, como afetividade primeira enquanto existida pela transcendência corporal. Uma vez postulada, essa estrutura existencial na qual o ser humano é fundamentalmente projeto de si na ambigüidade da retomada e recriação, cuja manifestação primeira é dada no corpo, a autora então acrescenta que se trata de um "élan em direção ao ser [élan vers l'être]" (Ibidem, p. 56) existido como paixão, como afirmação afetiva do existir. Neste contexto, Simone de Beauvoir lança mão de uma caracterização do que ela chama de "sub-homem [sous-homme]", ou seja, uma espécie de modo de existir humano problemático do ponto de vista ético e, neste caso, a partir da sua relação com a "paixão" do existir ${ }^{10}$. Segundo a autora, "o subhomem recusa esta paixão [passion] que é sua condição de homem", recusa o movimento ambíguo "deste élan em direção ao ser", que nada mais é do que buscar "reter esse movimento original" (Ibidem, p. 56, grifo nosso).

O problema fundamental seria que existir é afirmar esta paixão que nos lança e sustenta na existência, de modo que o sub-homem vive em uma contradição

\footnotetext{
10 Trata-se da compreensão da ética de Simone de Beauvoir como uma ética caracteriológica, como marcado por Joseph Mahon na medida em que na parte II de seu texto Beauvoir ofereceria "uma série de perfis de tipos humanos" (MAHON, 1997, p. 35) a partir da discussão do "sub-homem", "homemsério", "niilista", "aventureiro" e o "passional". Para os fins deste trabalho, discutiremos apenas as duas primeiras caracterizações.
}

TEIXEIRA, Nathan Menezes Amarante. Querer-se livre e querer-se moral é uma só e mesma decisão: Simone de Beauvoir e a 
interna quando continua a existir ao mesmo tempo em que nega, desdenha e recusa a própria afirmação deste existir. Em suma, trata-se da colocação de Beauvoir de que a paixão do élan em direção ao ser é já afirmação positiva da ambigüidade da existência e satisfeita de si mesma enquanto tal afirmação; essa paixão é um renovar da liberdade que "traz consigo tanto desgosto quanto alegria: desgosto com o colapso de certos projetos, mas ainda a alegria de achar suas mãos livres novamente e pronto para alongar-se em direção a um novo futuro" (MAHON, 1997, p. 43). É isto que o sub-homem recusa, pois "ao invés de assumir uma afetividade [affectivité] que o lançaria perigosamente mais além dele mesmo, ele a recusa" (BEAUVOIR, 2013, p. 61).

Outra característica importante apontada por Simone de Beauvoir acerca desta paixão positiva do existir diz respeito à afirmação do porvir que ela comporta. Assim, a "palavra porvir [avenir] tem dois sentidos, correspondentes aos dois aspectos da condição ambígua do homem, que é falta de ser e que é existência; é então como ser e como existência que ele será visado" (Ibidem, p. 143). Visar o porvir como existência é justamente visá-lo como desvelamento do ser, como movimento que prolonga meu existir presente com projetos que me abrirão a outros, mantendo aberto esse movimento do desvelar. Portanto, a afirmação de coincidir com essa paixão, de mantê-la positivamente como um querer-se livre, é manter na minha ação essa mesma afirmação do porvir como aberto, sem tomá-lo na perspectiva da "falta de ser", na qual este apareceria como um movimento progressivo necessário que seria retido no futuro ao fixar o ser faltado.

A partir destas considerações, explicita-se a identificação da autora de uma questão ética aberta pelo próprio existir humano. Nas suas palavras:

Se é verdade que todo projeto emana de uma subjetividade, é verdade
também que este movimento subjetivo coloca a partir de si mesmo um
ultrapassamento da subjetividade [dépassement de la subjectivité]. O homem
não pode encontrar uma justificação da sua existência se não na existência
dos outros homens. Ele tem a necessidade de tal justificação, não pode
escapar dela. A preocupação moral não vem ao homem de fora; ele trás nele
mesmo [ il trouve em lui-même] essa questão ansiosa: para que propósito? [
à quoi bom? ]. Ou, dizendo melhor, ele mesmo é esta interrogação urgente
[interrogation urgente]; ele não foge dela se não fugindo de si, e uma vez que
existe ele a responde. [...] Eu digo respeito aos outros e é a mim que eles
dizem respeito: a vinculação eu - outro é igualmente indissolúvel como a
vinculação sujeito-objeto. (Ibidem, pp. 91-92, grifo nosso).

Como nos mostra a citação, existir é cultivar as relações com os outros com os quais estamos enredados na situação, cultivo pois mantenho "fértil" esse solo comum ao querer positivamente a paixão que me lança no movimento de desvelar o ser. Assim, meu engajamento nesse projeto no qual me constituo subjetivamente já é um ir além desta subjetividade, pois é retomada dos projetos dos outros e simultaneamente abertura a seus projetos futuros, de modo que o próprio fazer-me existir coloca a necessidade da justificação daquilo que faço frente aos outros, coloca a questão sobre como meu agir será objetivado na situação para ser apelo aos demais. Para Beauvoir, existir é já responder a essa questão de algum modo, na medida em que existir é desvelar ser; portanto, querer-se ético é querer manter 
positivamente essa interrogação constante, é se preocupar ao modo como essa questão é respondida pelo meu agir no mundo, é não respondê-la na indiferença ou tentando encobri-la.

O conteúdo da ação ética, já indicado antes como querer-se livre, como afirmar efetivamente o movimento do existir de querer desvelar o ser, mostra-se então como liberação. Neste sentido, a ação é ética quando não busca construir uma situação fechada, quando busca a expansão da existência e já recupera tal esforço como absoluto, como abertura à possibilidade de retomá-lo no porvir. Define-se igualmente o que seria propriamente uma situação de opressão, como sendo uma situação fechada na qual o movimento do existir foi barrado. Segundo Simone de Beauvoir:

Minha liberdade exige para se realizar que ela se desenrole sobre um porvir
aberto [avenir ouvert]: são os outros homens que me abrem o porvir, são
eles que, constituindo o mundo de amanha, definem meu porvir; mas se,
ao invés de me permitir participar desse movimento construtivo [mouvement
constructeur] eles me obrigam a consumir de modo vão minha
transcendência, se eles me mantém aquém deste nível que conquistaram e
a partir do qual se efetuarão novas conquistas, então eles me cortam do
porvir, me transformam em coisa. A vida se empenha simultaneamente a se
perpetuar e a se ultrapassar [à se perpétuer et à se dépasser] se ela não faz
mais nada se não manter-se, viver é somente não morrer, e a existência
humana não se distingue de uma vegetação absurda. (Ibidem, p. 104, grifo
nosso).

Assim, o que a opressão faz é impedir o engajamento do indivíduo no movimento ambíguo de construção da situação, lhe entrega um porvir significado exclusivamente a partir do aspecto negativo da condição humana (falta de ser), de modo que só o aspecto negativo de manutenção da vida lhe resta como possível. Em suma, é uma situação que se lhe afigura como destino ${ }^{11}$, pois indica um ser fechado e decidido arbitrariamente como aquilo rumo ao qual sua vida deve necessariamente rumar para obter, enquanto algo fechado, sendo este fechamento a fixação daquilo que se é absolutamente, se é ao modo de ser das coisas.

Aqui novamente mostra-se a influência marxista dos Manuscritos, a partir da questão da alienação do trabalho. Como já indicado, o fundamento da existência humana é colocada por Marx na atividade produtiva comum que faz o ser humano parte da natureza e esta parte dele, assim, o trabalho como esta capacidade produtiva estruturada socialmente é determinado pela organização dos meios de produção. No capitalismo, como tal organização está fundada na propriedade privada, a forma social existente do trabalho será alienada em relação ao trabalhador que é alienado da organização dos meios de produção, apenas vive

\footnotetext{
11 Especificamente, somente em Le deuxième sexe, cuja primeira parte do primeiro volume chama-se "Destino [Destin]", que Simone de Beauvoir irá designar diretamente o discurso que visa estruturar e justificar uma situação de opressão como constituindo um destino ao individuo. Em Pour une morale de llambiguité não há uso direto da autora do termo "Destino", porém, como a situação de opressão descrita no livro posterior é dada a partir da mesma estrutura geral ética dos textos anteriores, visando marcar principalmente que é uma fixação do ser que constitui o individuo como algo absoluto, necessário e exterior, é oportuno fazermos uso já aqui de tal termo para melhor destacar a compreensão da autora.
}

TEIXEIRA, Nathan Menezes Amarante. Querer-se livre e querer-se moral é uma só e mesma decisão: Simone de Beauvoir e a 
precariamente suas conseqüências. Em suma, a "atividade produtiva constitui a fonte da consciência, e a 'consciência alienada' é o reflexo da atividade alienada ou da alienação da atividade, isto é, autoalienação do trabalho" (MÉZÁROS, 2016, p. 80). $O$ quadro geral mais detalhado dessa estrutura de alienação é dado por Marx nos seguintes termos:

\begin{abstract}
No trabalhador existe, pois, subjetivamente, [o fato] que o capital é o homem totalmente perdido de si, assim como existe, no capital, objetivamente, [o fato] de que o trabalho é o homem totalmente perdido de si. Mas o trabalhador tem a infelicidade de ser um capital vivo e, portanto, carente (bedürfitg), que, a cada momento em que não trabalha perde seus juros e, com isso, sua existência. Como capital, o valor do trabalhador aumenta no sentido da procura e da oferta e, também fisicamente, a sua existência, a sua vida, se torna e é sabida como oferta de mercadoria, tal como qualquer mercadoria. O trabalhador produz o capital; o capital produz o trabalhador. $\mathrm{O}$ trabalhador [produz], portanto, a si mesmo, e o homem enquanto trabalhador, enquanto mercadoria, é o produto do movimento total. O homem nada mais é do que trabalhador e, como trabalhador, suas propriedades humanas o são apenas na medida em que o são para o capital, que lhe é estranho (MARX, 2004, p. 91).
\end{abstract}

O fundamental de tal compreensão consiste em que, ao ser reduzido socialmente segundo interesses privados à mera produção de mercadorias, o trabalho humano vira igualmente mercadoria, de modo que tanto a dimensão subjetiva quanto objetiva da existência do indivíduo serão expressão dessa relação do trabalho como mercadoria alienada. Assim, ao invés de a atividade produtiva realizar-se como mediação adequada entre os indivíduos e sua situação, onde cada um manifesta-se como ser humano livre para si e para os outros, acaba por ser fundamentalmente negação desta liberdade, é mediação alienada vivida como necessidade. Nos vários aspectos da alienação descritos por Marx, tem-se como fundamental que "a alienação aparece dissociando o individual do social" (MÉZÁROS, 2016, p. 161) e alienando sua liberdade, na medida em que "o homem (o trabalhador) só se sente como [ser] livre e ativo em suas funções animais [...] e em suas funções humanas só se sente como animal" (MARX, 2004, p. 83).

O principal da situação de opressão apresentada por Simone de Beauvoir é justamente que nela o indivíduo encontra-se alienado da sua dimensão mais fundamental, o movimento livre de desvelamento do ser, pelas estruturas objetivas que fazem tal movimento ser usado para os fins do opressor. Assim, sua existência propriamente humana e livre é vivida como facticidade, viver é somente não morrer para sustentar tal situação, posto que a dimensão positiva da transcendência foi negada e aparece objetivamente frente ao oprimido como algo exterior, movimento do qual ele não faz parte. Por sua vez, também há aqui a dissociação do indivíduo do campo social, posto que tal campo é a estrutura da situação como apelo a ser respondido positivamente, porém, dado sua situação ser fechada, a ligação concreta da liberdade e situação que marca a interdependência dos projetos humanos aparece mistificada na ideia da relação com os outros ser necessariamente conflituosa, culminando em uma compreensão individualista de liberdade.

Neste âmbito da discussão, se mostra significativo o uso feito por Simone de Beauvoir de outra exemplificação de um modo de existir problemático do ponto de 
vista ético, o "homem sério". Sua característica principal seria a de se desvincular "de sua liberdade ao pretender subordiná-la a valores que seriam incondicionais; ele imagina que o acesso a esses valores o valoriza a si-mesmo de modo permanente" (Ibidem, p. 61). O homem sério nega sua liberdade tal como o sub-homem, porém trata-se de uma negação em nome de valores prontos e abstratos que ele aceita como um ser a se obter fixamente; em nome de ideias gerais como "O Bom", "O Estado", "O Progresso" etc., ele concebe o movimento do existir como realização obrigatória de tais ideias, que seriam então mais importantes do que as vidas humanas por meio das quais estes valores se efetivam.

O problema ético de tal modo de existir é precisamente que os valores transformam-se em "ídolos inumanos em nome dos quais não se hesitará em sacrificar o homem mesmo" ou seja, "é natural que ele faça-se tirano"(Ibidem, p. 64). Tal fanatismo do homem sério criaria justamente as situações fechadas que impedem que o indivíduo queira o desvelamento do ser, ao poder querê-lo apenas como um "ídolo" - alienado, em termos marxistas - que dá o "destino" de sua existência. É ainda aqui que a problemática ética do sub-homem torna-se mais explícita, pois "em todos os grandes movimentos sangrentos [...] que organiza o fanatismo do sério, é entre os sub-homens que se recruta a mão de obra" (Ibidem, p. 58). A questão central é que, negando o movimento ambíguo do existir, o sub-homem nega precisamente o desvelamento do mundo, a criação de relações afetivamente significativas a partir das quais lançamo-nos positivamente a nossos projetos, de modo que seu existir é um constante tédio no qual "ele sente o deserto do mundo" (Ibidem, p. 59). Indiferente à sua situação, aos outros e a si, o sub-homem aceita tranquilamente mover-se como puro nada guiado pelas organizações igualmente vazias dos valores do homem sério.

Consequentemente, a questão da liberdade como liberação, trabalhada anteriormente, coloca necessariamente a problemática da violência, pois é como violência que esta se mostra ao ir de encontro ao fechamento de uma situação. No entanto, segundo Simone de Beauvoir, a resposta a tal problemática encontra-se já dada pela própria identificação do querer-se livre com o querer a manutenção do movimento de desvelamento do ser. Então, se querer-se ético é querer o "triunfo da liberdade sobre a facticidade" (Ibidem, p, 121), este também se colocará diante de uma situação específica de opressão como querendo sua supressão, pois esta é precisamente o encerramento do existir à pura facticidade do manter-se, da repetição sem transcendência, o que é feito por uma violência que busca fechar uma existência que é inicialmente abertura. Assim, "uma liberdade que se emprega somente para negar a liberdade do outro deve ser negada" (Ibidem, p. 113), de modo que a única atitude do oprimido diante da violência do opressor é negar violentamente a "harmonia desta humanidade da qual pretendem o excluir" (Ibidem, p. 104), pois só assim ele retoma a abertura de sua situação. Por sua vez, mesmo para aquele que não se encontra na situação de opressão, a urgência ética do seu próprio existir coloca a necessidade de que ele se engaje na abertura dessa situação do outro, abertura que só pode dar-se como violência contra as estruturas visando abrir um porvir que nega o porvir fechado projetado pelo opressor.

Segundo Beauvoir, não se trata de colocar a ação liberadora como não violenta, mas antes analisá-la corretamente do ponto de vista da situação, que a diferencia da violência do opressor. Por sua vez, colocar ambas as violências no 
mesmo nível ético de análise seria adotar o que a autora aponta como uma "atitude estética" frente a tal problema, que admite poder colocar-se fora do mundo e desvinculado de qualquer situação para fazer um ajuizamento absoluto, no qual todas as situações se equivalem. Se a liberdade é retomar e recriar da situação, as possibilidades concretas do oprimido de manter tal movimento encontram-se barradas como situação desfavorável em relação à daquele que o limita, de modo que sua violência enquanto retomada do movimento do existir é a única afirmação ética possível de si frente à negação antiética que lhe é feita do exterior ${ }^{12}$.

Por fim, à luz dessas considerações, torna-se mais claro a afirmação de Simone de Beauvoir, já indicada aqui, de que a ação positiva e ética da liberdade faz-se quando esta busca "um fim que não é alguma coisa, mas precisamente o livre movimento da existência" (Ibidem, p. 38). Trata-se aqui da colocação de Simone de Beauvoir de que o existir humano, por ser ambíguo, não se enquadra em uma estrutura tradicional de meios e fins ${ }^{13}$; a liberdade que quer desvelar o ser não o quer como mero meio para algo externo, nem como fim último a ser obtido, ela o quer como meio que já é fim, quer o desvelamento (meio) como afirmação do mesmo desvelar (fim) que realiza-se já no próprio meio ${ }^{14}$. Tal aspecto observa-se também na relação entre presente e porvir, pois o desvelamento do ser afirma o presente como apelo ao porvir, e este último como apelo retrospectivo sobre o presente que ele transcende, levando mais além. A ação ética, portanto, visa a liberação que "não é uma coisa situada em um tempo estrangeiro, mas um movimento que se realiza tendendo a conquistar a si" (Ibidem, p. 162), ou seja, busca uma forma concreta de existir na qual seus diferentes momentos se remetem uns aos outros se confirmando e se justificando em relação a esse querer-se a si da liberdade "uma vez que não há mais um corte separador [séparation tranchée] entre presente e porvir, meios e fins" (Ibidem, p. 162).

É oportuno apontar que, conforme vimos na definição da opressão, Beauvoir a designa precisamente como aquela na qual a existência do indivíduo entra em uma estruturação de meios e fins pela violência do opressor. Ou seja, ao fundamentar uma determinada situação singular como destino, como fechada, o que o opressor faz é precisamente impedir o desenvolvimento do desvelamento do ser que é meio e fim ao mesmo tempo, assim, a existência do indivíduo assim encerrado aparece para si como mero meio para manter-se e repetir-se em direção ao fim absoluto, que é o ser definido exteriormente. A violência que sofre é a violência de se estruturar arbitrariamente uma existir em uma lógica que o faz mero meio vazio e negativo para consecução de fins estrangeiros, e a violência que este opera como liberação é a recusa de tal estruturação, recusa de que sua situação seja meio passivo para a realização de um destino.

\footnotetext{
12 "a violência não será justificada a não ser que ela abra as possibilidades concretas a esta liberdade que eu pretendo salvar" (BEAUVOIR, 2013, p. 170, grifo nosso).

13 Beauvoir já havia trabalhado isso em Pyrrhus et Cinéas, conforme vemos em sua colocação de que "a noção de fim é ambígua pois todo fim é ao mesmo tempo ponto de partida; mas isso não impede que este seja visado como fim: é neste ser possível que reside liberdade do homem" (Ibidem, p. 223). 14 "o propósito não é fixado de uma vez por todas, ele se define ao longo do caminho que o conduz" (Ibidem, p. 189).
} 
Entretanto, esse querer-se livre não garante que toda ação será necessariamente ética, justamente por isso que Beauvoir aponta a importância de se compreender que "a moralidade reside na dor de uma interrogação indefinida" (Ibidem, p. 165), não somente no sentido de que existir é ser esta interrogação, mas fundamentalmente de que existir autenticamente é estar constantemente engajado em uma constituição ética e subjetiva ininterrupta, distanciando-se da atitude do homem sério que pensa a moralidade como adesão absoluta a valores abstratos. Uma moral dada a partir da condição ambígua do existir humano, que busca um princípio válido para cada indivíduo separado e enredado em uma situação comum, pode oferecer um método mais geral (a afirmação positiva do movimento do existir) "mas não pode definir a priori o momento de invenção" (Ibidem, p. 166) que é dado na consideração da relação ambígua deste princípio com cada situação particular. Neste sentido, mantendo positivamente a questão ética aberta pelo desvelamento do ser, tem-se que "ao colocar seus fins, a liberdade deve os colocar entre parênteses, os confrontar a cada momento com este fim absoluto que constitui ela mesma e contestar em seu próprio nome os meios os quais ela usa para se conquistar (Ibidem, p. 166).

Deste modo, caso o conteúdo concreto da ação (que é fim particular e ao mesmo tempo meio no qual se realiza o fim último como movimento do existir que quer a si) negue o sentido da ação, ou seja, o fim último (movimento do existir que também é meio de realização dos fins particulares), então "é preciso modificar não o sentido [sens], que é desejado aqui absolutamente, mas o conteúdo mesmo" (Ibidem, p. 167). O fim último também deve ser meio, ou seja, deve estar aberto e realizado nas ações concretas da liberdade, de modo que se determinada conduta mostrar-se problemática em uma determinada situação, como negando a recuperação posterior do desvelamento do ser, essa conduta deverá ser revista à luz das especificidades da situação, de maneira que seja possível alterar esse conteúdo para que o desvelamento do ser seja recuperado em possibilidades concretas liberadas. Tal esquema ganha maior concretude quando a autora postula que

\footnotetext{
Não se pode esquecer que há uma ligação concreta [lien concret] entre liberdade e existência; querer o homem livre é querer que haja ser, é querer o desvelamento do ser no prazer da existência; para que a ideia de liberação tenha um sentido concreto é preciso que o prazer de existir seja afirmado em cada um, a cada instante; é ganhando espessura em prazer, em felicidade, que o movimento em direção à liberdade toma no mundo uma figura carnal e real [charnelle et réelle]. [...] a economia do tempo, a conquista do laser não tem nenhum sentido se o riso de uma criança que vive prazerosamente não nos toca. Se nós não amamos a vida por nosso própria conta e através do outro, é vão buscar justificá-la de alguma maneira (Ibidem, p. 166, grifo nosso).
}

É em situação que a liberdade ontológica humana ganha sua "forma carnal" e abre-se à existência, ao afirmar-se a si e ao próprio existir como prazer e alegria no seu engajamento entrelaçado com os outros, de modo que querer-se livre é querer possibilidades concretas, portanto situadas abertamente, de realização de tal 
afirmação simultânea de si mesmo e dos demais ${ }^{15}$. Só uma situação, enquanto mediação ambígua entre o movimento livre subjetivo e seu simultâneo ultrapassamento no existir social, cultivada à luz do desvelamento do ser, é que permite que cada um assuma autêntica, ética e prazerosamente sua existência por sua própria conta $e$ através dos outros, portanto, querer existir livre e eticamente é querer positivamente ser o movimento ambíguo de retomada e recriação do estar situado; em suma, "querer-se moral e querer-se livre é uma só e mesma decisão" (Ibidem, p. 32).

\footnotetext{
15 Em um ensaio publicado em 1945 no Les temps modernes, intitulado "Existencialismo e a sabedoria das nações [L'existentialism et la sagesse des nations]", Beauvoir, buscando responder à crítica de que o existencialismo seria fundamentalmente niilista e subjetivista, respectivamente pelo apontamento da negatividade presente na existência humana e pelo foco na liberdade individual, nos dá a seguinte definição: "O que é importante é como o homem ultrapassa sua situação. A separação das consciências é um fato metafísico, porém, o homem pode superá-lo. Ele pode, através do mundo, unir a si mesmo aos outros homens. Os existencialistas estão tão longe de negar o amor, a amizade e o companheirismo que, a seus olhos, o único modo dos indivíduos encontrarem a fundamentação e realização de seu ser é nestas relações humanas" (BEAUVOIR, 2004, p. 211). Tal citação reforça a compreensão de uma definição de existencialismo própria de Beauvoir oposta à de Sartre, com uma preocupação fundamentalmente ética a partir da ambigüidade existencial que faz com que a justificação da vida individual seja dada na sua afirmação do enraizamento na dimensão coletiva, já dada em Pyrrhus et Cineas, colocado mais explicitamente no ensaio citado e retrabalhado em Por une morale de l'ambiguité, como mostramos aqui.
}

TEIXEIRA, Nathan Menezes Amarante. Querer-se livre e querer-se moral é uma só e mesma decisão: Simone de Beauvoir e a 


\section{Referências Bibliográficas}

CARD, Claudia. Introduction: Beauvoir and the ambiguity of "ambiguity" in ethics. In:

CARD, Claudia (org.). The Cambridge companion to Simone de Beauvoir. Cambridge: Cambridge University Press, 2003.

ARP, Kristiana. Beauvoir as situated subject: The ambiguities of life in World War II France. In: O'BRIEN, Wendy (Ed.). The existential phenomenology of Simone de Beauvoir. Nova York: Springer Verlag Press, 2001.

BEAUVOIR, Simone de. Pour une morale de l'ambiguité suivi de Pyrrhus et Cinéas. Paris: Gallimard, 2013.

BEAUVOIR, Simone de. Political idealism, moral realism. In: SIMMONS, Margaret (Ed.). Simone de Beuavoir: Philosophical Writtings. Illinois: University of Illinois Press, 2004.

BEAUVOIR, Simone de. Existentialism and Popular Wisdow. In: SIMMONS, Margaret (Ed.). Simone de Beuavoir: Philosophical Writtings. Illinois: University of Illinois Press, 2004.

BOUCHER, Geoff. Marxismo. Rio de Janeiro: Editora Vozes, 2012.

GOTHLIN, Eva. Simone de Beauvoir's existential phenomenology and philosophy of history in Le deuxième sexe. In: O'BRIEN, Wendy (Ed.). The existential phenomenology of Simone de Beauvoir. Nova York: Springer Verlag Press, 2001.

GOTHLIN, Eva. Reading Simone de Beauvoir with Martin Heidegger. In: CARD, Claudia (Org.). The Cambridge companion to Simone de Beauvoir. Cambridge: Cambridge University Press, 2003.

HEIDEGGER, Martin. Sein und Zeit. Berlin: Verlag Tübingen, 1967.

KAIL, Michel. Simone de Beauvoir philosophe. Paris: PUF, 2015.

KRUKS, Sonia. Simone de Beauvoir and the politics of ambiguity. Oxford: Oxford University Press, 2012.

MAHON, Joseph. Existentialism, feminism and Simone de Beauvoir. London: Macmillan Press, 1997.

MARX, Karl. Manuscritos econômico - filosóficos. São Paulo: Boitempo Ed., 2004. MARX, Karl. Crítica da filosofia do direito de Hegel. São Paulo: Boitempo Ed., 2010. MÉZÁROS, István. A teoria da alienação em Marx. São Paulo: Boitempo Ed., 2016. MILLER, Richard. Social and political theory: Class, state, revolution. In: CARVER, Terrell (Ed.). The Cambridge Companion to Marx. Cambridge: Cambridge University Press, 2006.

POSTER, Mark. Existential Marxism in Postwar France: From Sartre to Althusser. New Jersey: Princeton University Press, 1975.

REYNOLDS, Jack. Existencialismo. Rio de Janeiro: Editora Vozes, 2014.

Autor(a) para correspondência: Nathan Menezes Amarante Teixeira, Universidade Federal do Rio de Janeiro, Instituto de Filosofia e Ciências Sociais, Largo São Francisco de Paula, 1, Centro, CEP 20051-070, Rio de Janeiro - RJ, Brasil.nathanmateixeira@gmail.com 